\title{
Mouen - Rue Pierre Castel
}

$n^{\circ} 3388$

\section{Benjamin Hérard}

\section{(2) OpenEdition \\ Journals}

Édition électronique

URL : http://journals.openedition.org/adlfi/16987

ISSN : 2114-0502

Éditeur

Ministère de la culture

Référence électronique

Benjamin Hérard, « Mouen - Rue Pierre Castel », ADLFI. Archéologie de la France - Informations [En ligne], Basse-Normandie, mis en ligne le 16 mars 2016, consulté le 19 avril 2019. URL : http:// journals.openedition.org/adlfi/16987

Ce document a été généré automatiquement le 19 avril 2019

(c) Ministère de la Culture et de la Communication, CNRS 


\section{Mouen - Rue Pierre Castel}

$n^{\circ} 3388$

\section{Benjamin Hérard}

Lien Atlas (MCC) :

http://atlas.patrimoines.culture.fr/atlas/trunk/index.php?

ap_theme=DOM_2.01.02\&ap_bbox=-0.504;49.135;-0.471;49.160

1 L'opération de diagnostic prescrite sur la seconde phase d'aménagement du lotissement $\mathrm{du}$ Lieu Castel à Mouen concernait une surface d'environ deux hectares située immédiatement à l'est des terrains actuellement en cours d'aménagement et étudiés en 2012. Les sondages de 2013 ont permis de repérer plusieurs trames de fossés, sans doute parcellaires, attribuables pour l'une à la Protohistoire et plus vraisemblablement à l'âge du Fer, et pour les deux autres, à la période gallo-romaine.

2 Les fossés protohistoriques, au nombre de deux, se raccordent au parcellaire et aux bords nord et sud du petit enclos sub-quadrangulaire de l'âge du Fer, repérés lors de la précédente phase de diagnostic réalisée en 2012. Seule une fosse colmatée par un gros fragment de meule en grès figure dans l'inventaire des structures pouvant être associées à ce réseau. Si l'opération de 2012 n'avait permis de collecter qu'une petite quantité de mobilier archéologique associé aux fossés protohistoriques, l'exploration de 2013 s'est avérée totalement stérile en la matière.

Les fossés antiques semblent organisés selon deux systèmes d'orientation distincts. Le premier d'entre eux, axé nord-sud et perpendiculairement, se développe dans les deux tiers nord de la parcelle, apparemment en marge du gisement protohistorique. À cette organisation vient s'en raccorder une seconde dont les lignes directrices s'infléchissent de $20^{\circ}$ dans le sens de la légère pente du terrain. Le mobilier collecté dans les fossés est attribuable au Haut-Empire avec notamment la découverte d'un petit pot globulaire en céramique commune datable $\mathrm{du} \mathrm{II}{ }^{\mathrm{e}} \mathrm{s}$. apr. J.-C. Aucune structure ponctuelle associée à ce réseau de fossés n'a été détectée. 
INDEX

operation Diagnostic (EV)

Index géographique : Basse-Normandie, Calvados (14), Mouen

Mots-clés : fossé, enclos, céramique, pot

Index chronologique : Gallo-romain

\section{AUTEURS}

BENJAMIN HÉRARD

Inrap 